\title{
Effect of Moisture Stress on Leaf Relative Water Content (RWC) of Four Cowpea (Vigna unguiculata L. walp.) Genotypes at Different Stages of Growth
}

\author{
P.B. Kardile ${ }^{1 *}$, K.N. Dahatonde ${ }^{2}$, M.V. Rakshe ${ }^{1}$ and M.M. Burondkar ${ }^{1}$ \\ ${ }^{1}$ Department of Agricultural Botany, COA, Dapoli, DBSKKV, Dapoli. (M.S.), India \\ ${ }^{2}$ Department of Horticulture, MPKV, Rahuri, India \\ *Corresponding author
}

\begin{abstract}
A B S T R A C T
Present research was conducted to assess the performance of four cowpea genotypes (Fodder cowpea-1, konkan sadabahar, ACP-109, PCP-9702-1) under moisture stress conditions, at research farm Department of Agricultural Botany, COA, Dapoli, DBSKKV,

\begin{tabular}{|l|}
\hline Keyw ord s \\
Cowpea, RWC, \\
Moisture stress \\
\hline Article Info \\
\hline Accepted: \\
23 March 2018 \\
Available Online: \\
10 April 2018 \\
\hline \hline
\end{tabular}
Dapoli (M.S.). At harvest, the highest relative water content was found in genotype Konkan sadabahar (83.54), which was significantly superior over all the genotypes. The lowest relative water content was found in genotype PCP-9702-1 (76.20). Relative water content of leaf (RWC) indicates the actual water content to its maximum turgidity. From 45 DAS onwards, the difference in relative water content in all varieties due to water stress treatments became more and more prominent. Relative water content of leaf (RWC) indicates the actual water content to its maximum turgidity. It was observed that, plants under zero stressed condition had maintained higher RWC throughout the course than strong stressed and severe stressed plants. At 90 DAS, genotypes fodder cowpea-1 and ACP-109 showed less reduction in RWC under strong (4.23\%), (5.09\%) and severe $(13.72 \%),(14.81 \%)$ stressed conditions than all other genotypes studied. These genotypes showed better maintenance of higher RWC ensuring better hydration and more favourable internal water relations of tissue with a possibly higher pressure potential and showed better drought tolerance capacity.
\end{abstract}

\section{Introduction}

Pulses have been recognized as a major source of vegetable protein with needed minerals and vitamins. They play a vital role in maintaining soil fertility by fixing atmospheric nitrogen. Among pulses, Cowpea (Vigna unguiculata (L.) Walp.) is most important legume crop in Asia, Africa, Australia and U.S.A. Water stress is the most common adverse situation which affects the production of agricultural crops all over the world. Konkan region of Maharashtra represents a typical contrasting situation of ample availability of water through assured and heavy monsoon rainfall (average $3,500 \mathrm{~mm}$ ) occurring rigidly only during June to October on one hand and everincreasing terminal water stress caused by a high infiltration rate $(4.4 \mathrm{~cm} / \mathrm{hr})$, poor water holding capacity (27.15 to 30.30 per cent at field capacity and 16.60 to 18.10 per cent at P.W.P. (Dongale et al., 1987) on the other 
hand. Practically no rainfall from October to May accentuates the strength of water stress which limits the yield of field crops, commonly the grain legumes viz., cowpea, horsegram, lablab bean etc. which are grown on stored soil moisture in rice fallows during post monsoon season. It is well known fact that cowpea has greater developmental plasticity than some of the cultivated legumes which imparts it drought tolerance. The present study was studied to reveal the component traits responsible for developmental plasticity and mechanism of sustaining yield levels in water deficit conditions with support of growth analysis and biochemical investigation; To investigate the impact of moisture stress on morphophysiological traits of cowpea genotypes; To study the impact of moisture stress on various growth parameters and biochemical parameters of cowpea genotypes; To find out moisture stress tolerant, high yielding and high biomass producing genotypes of cowpea.

\section{Materials and Methods}

The experimental material for the study consisted of 4 genotypes of cowpea. The seeds of four cowpea genotypes were collected from Research farm, Department of Agricultural Botany, College of Agriculture, Dapoli. The experiment comprised of 4 genotypes of cowpea laid out in split plot Design with three replications provided with three different moisture stress levels. The experiment was conducted in Split Plot Design with three replications. The stress treatments were imposed at three different levels.

In first moisture stress treatment, crop was grown on control with zero stress from sowing to maturity. In second moisture stress treatment, cowpea crop was subjected to moisture stress from pre flowering to maturity, i.e. with helding irrigations from $40 \mathrm{DAS}$; and third stress treatment was taken as cowpea crop was grown on available residual soil moisture from sowing to the maturity.

\section{Results and Discussion}

\section{Mean relative water content (RWC)}

The data on relative water content as influenced by different stress treatments are presented in Table 1 and figure 1. Data indicated significant differences in relative water content amongst 4 genotypes during different crop growth stages as, 30, 45, 60, 75 and at 90 DAS. Mean values over all 4 genotypes recorded for this parameter were 79.34, 71.90, 74.27, 79.91 and $80.02 \%$ during the period of $30,45,60,75$, and at 90 DAS respectively.

\section{Main effect of moisture stress}

At 30 DAS, the mean relative water content of plants under Zero stress and under strong stress treatments were statistically at par with each other and showed greater relative water content than severe stress treatment. From 45 DAS onwards, the difference in relative water content in all varieties due to stress treatments became more and more prominent. At 60 DAS, the pattern of variation in relative water content was as zero stress (88.52), strong stress (72.58) and in severe stress (61.70). Whereas, at 75 DAS, it was as in zero stress (88.19), strong stress (77.96) and in severe stress (72.85). The varietal variation in relative water content was also significant at many growth stages.

\section{Varietal differences}

At 45 DAS, the highest mean relative water content was observed in genotype Konkan sadabahar (76.07), followed by fodder cowpea-1 (73.06). The lowest relative water content was found in genotype ACP-109 (71.94) followed by PCP-9702-1 (66.49). 
Table.1 Effect of various degrees of moisture stress on Leaf relative water content in cowpea genotypes at various phases of plant growth

\begin{tabular}{|c|c|c|c|c|c|c|}
\hline \multirow[t]{2}{*}{ Genotypes } & \multicolumn{4}{|c|}{ Degrees of water stress } & \multirow[t]{2}{*}{$\mathbf{S E} \pm$} & \multirow{2}{*}{$\begin{array}{l}\text { CD at } \\
5 \%\end{array}$} \\
\hline & Zero & Strong & Severe & Mean & & \\
\hline \multicolumn{7}{|c|}{30 DAS } \\
\hline Fodder Cowpea -1 & 82.25 & 81.71 & 77.79 & 80.58 & V. 0.0532 & 0.1555 \\
\hline PCP 9702-1 & 75.37 & 75.97 & 73.60 & 74.98 & S. 0.0358 & 0.1376 \\
\hline Konkan sadabahar & 81.27 & 81.04 & 76.67 & 79.66 & $\mathrm{~S} \times \mathrm{V} 0.1597$ & 0.4976 \\
\hline ACP -109 & 83.81 & 83.96 & 78.65 & 82.14 & & \\
\hline Mean & 80.68 & 80.67 & 76.68 & 79.34 & & \\
\hline \multicolumn{7}{|c|}{45 DAS } \\
\hline Fodder Cowpea -1 & 80.43 & 73.51 & 65.25 & 73.06 & V. 0.0571 & 0.1670 \\
\hline PCP 9702-1 & 72.82 & 67.24 & 59.42 & 66.49 & S. 0.0551 & 0.2116 \\
\hline Konkan sadabahar & 83.18 & 76.38 & 68.68 & 76.08 & $\mathrm{~S} \times \mathrm{V} 0.1715$ & 0.5570 \\
\hline ACP -109 & 79.76 & 72.58 & 63.50 & 71.95 & & \\
\hline Mean & 79.05 & 72.43 & 64.21 & 71.90 & & \\
\hline \multicolumn{7}{|c|}{60 DAS } \\
\hline Fodder Cowpea -1 & 89.33 & 74.79 & 62.55 & 75.56 & V. 0.1047 & 0.3060 \\
\hline PCP 9702-1 & 85.95 & 64.39 & 55.36 & 68.57 & S. 0.1019 & 0.3911 \\
\hline Konkan sadabahar & 91.87 & 78.41 & 68.19 & 79.49 & $\mathrm{~S} \times \mathrm{V} 0.3141$ & 1.0215 \\
\hline ACP -109 & 86.96 & 72.75 & 60.74 & 73.48 & & \\
\hline Mean & 88.53 & 72.59 & 61.71 & 74.27 & & \\
\hline \multicolumn{7}{|c|}{75 DAS } \\
\hline Fodder Cowpea -1 & 89.18 & 82.37 & 74.32 & 81.96 & V. 0.1288 & 0.3763 \\
\hline PCP-9701-2 & 83.38 & 66.40 & 65.47 & 71.75 & S. 0.1081 & 0.4149 \\
\hline Konkan sadabahar & 93.70 & 82.89 & 75.32 & 83.97 & $\mathrm{~S} \times \mathrm{V} 0.3864$ & 1.2333 \\
\hline ACP -109 & 87.39 & 81.77 & 76.72 & 81.96 & & \\
\hline Mean & 88.41 & 78.36 & 72.96 & 79.91 & & \\
\hline \multicolumn{7}{|c|}{90 DAS } \\
\hline Fodder Cowpea -1 & 86.11 & 82.47 & 74.30 & 80.96 & V. 0.0467 & 0.1365 \\
\hline PCP 9702-1 & 82.34 & 75.64 & 70.63 & 76.20 & S. 0.0451 & 0.1731 \\
\hline Konkan sadabahar & 93.60 & 81.58 & 75.47 & 83.55 & \multirow[t]{3}{*}{$\mathrm{S} \times \mathrm{V} 0.1402$} & \multirow[t]{3}{*}{0.4554} \\
\hline ACP -109 & 85.60 & 81.25 & 71.31 & 79.39 & & \\
\hline Mean & 86.91 & 80.23 & 72.93 & 80.02 & & \\
\hline
\end{tabular}

V. - Variety S. - Stress $S \times V$. - Stress $\times$ Variety 


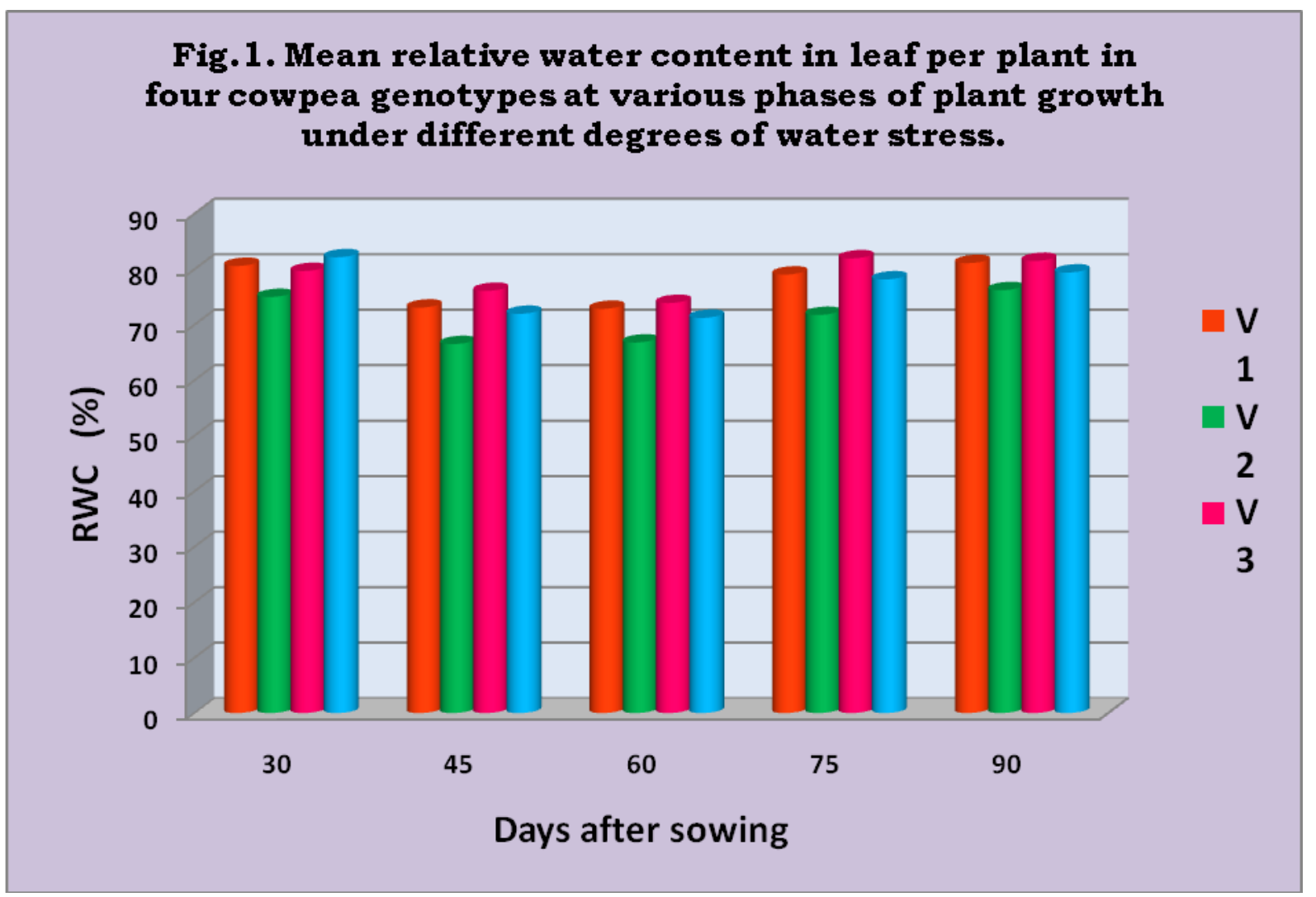

At 60 DAS, the maximum relative water content was found in genotype Konkan sadabahar (79.49), which was significantly superior over all the genotypes. The lowest relative water content was found in genotype PCP-9702-1 (68.56) which was significantly lowest compared to all the genotypes.

At 75 DAS, the highest relative water content was found in genotype Konkan sadabahar (83.96) followed by, ACP-109 (81.95) and fodder cowpea (81.957), which were at par with each other.

The lowest relative water content was found in genotype PCP-9702-1 (71.75), which was significantly lowest over all the genotypes.

At harvest, the highest relative water content was found in genotype Konkan sadabahar (83.54), which was significantly superior over all the genotypes. The lowest relative water content was found in genotype PCP-9702-1
(76.20). Relative water content of leaf (RWC) indicates the actual water content to its maximum turgidity. From 45 DAS onwards, the difference in relative water content in all varieties due to water stress treatments became more and more prominent. At 90 DAS, genotypes fodder cowpea-1, followed by ACP-109 showed less reduction in RWC under strong $(4.23 \%),(5.09 \%)$ and severe $(13.72 \%),(14.81 \%)$ stressed conditions than two other genotypes studied.

This is because of genotypes showed better maintenance of higher RWC ensuring better hydration and more favorable internal water relations of tissue with a possibly higher pressure potential and showed better drought tolerance capacity (Chavan and Janagoudar, 2007). The varietal differences for RWC in cowpea and pulse crops were also reported by Maharaj Singh et al., (2009), Parab (1991), Shinde (1998) and Reddy et al., (2000). Relative water content of leaf (RWC) 
indicates the actual water content to its maximum turgidity. It was observed that, plants under zero stressed condition had maintained higher RWC throughout the course than strong stressed and severe stressed plants. These genotypes showed better maintenance of higher RWC ensuring better hydration and more favourable internal water relations of tissue with a possibly higher pressure potential and showed better drought tolerance capacity.

In conclusion, it is to be stated that, a wide range of variability existed for the different growth and yield parameters among 4 cowpea genotypes. Among four genotypes of cowpea studied, under three different water stress conditions genotypes, fodder cowpea-1 followed by konkan sadabahar recorded high yield under severe stressed condition, genotypes fodder cowpea-1 and ACP-109 showed less reduction in RWC under strong $(4.23 \%),(5.09 \%)$ and severe (13.72\%), $(14.81 \%)$ stressed conditions than all other genotypes studied. This showed attributed to better yield.

This information may be helpful for better understanding of concepts of critical stages of vegetative and reproductive growth and its applications to the effect of drought on various aspects of growth and yield of cowpea. It can be employed for crop improvement programme as well as efficient management practices for cowpea production in drought prone conditions.

\section{References}

Hsaio, T.C. (1973). Plant response to water stress. Ann. Rev.Pl. Physiol., 24: 519570.

Maharaj Singh, J.S. Chauhan and S. S. Meena (2009). Drought induced changes in water use efficiency and other morphophysiological characters in Indian mustard (Brassica juncea L.) 16th Australian Research Assembly on Brassicas. Ballarat Victoria 2009.

Mukesh L. Chavan, Janagoudar, B.S., Dharmatti, P.R., Koti, R.V., Ravindera Mulge, Dinakar J. Adiga and Shashidhar, T.R., 2007, Change in yield contributing characters of tomato (Solanum lycopersicum L.) genotypes as affected by drought stress. J. Asian Hort. 4(1): 4-7. 40.

Parab, B. (1991). Effect of different levels of potassium nutrition on growth and yield of cowpea (Vigna unguiculata) variety VCM-8 under the moisture stress at different phases of growth. Thesis submitted for M.Sc (Agri.) programme to KKV, Dapoli (1991) pp.18.

Reddy, P.V. and Asalatha, M. (2000). Relationship of mineral ash and chlorophyll content with transpiration efficiency in groundnut under different moisture regions. Indian J.Plant. Physiol. 5: 59- 63.

Shinde A.K. (1998). Alleviation of drought in five legumes. A Ph.D. thesis submitted to DBSKKV, Dapoli (M.S.)

\section{How to cite this article:}

Kardile, P.B., K.N. Dahatonde, M.V. Rakshe and Burondkar, M.M. 2018. Effect of Moisture Stress on Leaf Relative Water Content (RWC) of Four Cowpea (Vigna unguiculata L. walp.) Genotypes at Different Stages of Growth. Int.J.Curr.Microbiol.App.Sci. 7(04): 2645-2649. doi: https://doi.org/10.20546/ijcmas.2018.704.301 